\title{
Vapor-phase catalytic dehydration of lactic acid to acrylic acid over nano-crystalline cerium phosphate catalysts
}

\author{
Nekkala Nagaraju ${ }^{1} \cdot$ Vanama Pavan Kumar $^{1} \cdot$ Amirineni Srikanth $^{1} \cdot$ \\ N. Pethan Rajan ${ }^{1} \cdot$ Komandur V. R. Chary ${ }^{1}$
}

Received: 1 December 2015/Accepted: 18 March 2016/Published online: 1 April 2016

(c) The Author(s) 2016. This article is published with open access at Springerlink.com

\begin{abstract}
A series of cerium phosphate $(\mathrm{CeP})$ catalysts were synthesized using precipitation method with varying $\mathrm{Ce} / \mathrm{P}$ mole ratios ranging from 0.5 to 3.0 followed by calcination. The formation of cerium phosphate was confirmed by X-ray diffraction and FT-IR techniques. The catalysts were further characterized to understand the morphology, surface area by using transmission electron microscopy (TEM) and $\mathrm{N}_{2}$-sorption measurements. The acidic and basic sites were measured by $\mathrm{CO}_{2}-\mathrm{TPD}, \mathrm{NH}_{3}$ TPD and ex situ pyridine FT-IR methods. These calcined $\mathrm{CeP}$ catalysts were employed for the dehydration of lactic acid (LA) to acrylic acid (AA) under vapor-phase reaction conditions. Among the catalysts examined, CeP catalyst with $\mathrm{Ce} / \mathrm{P}$ mole ratio $2.5(\mathrm{CeP}(2.5))$ was found to exhibit better catalytic performance with conversion of lactic acid $\sim 100$ and $64 \%$ selectivity towards acrylic acid at optimized conditions. Time-on-stream experiments suggest that $\mathrm{CeP}(2.5)$ catalyst exhibited constant activity until $20 \mathrm{~h}$ after which a slight drop of conversion of lactic acid was noticed. The characterization studies of the spent catalysts using thermogravimetric (TG), CHNS analysis and FT-IR reveal the presence of carbonaceous species over the catalyst surface causing deactivation of the catalyst.
\end{abstract}

Keywords Lactic acid (LA) - Acrylic acid (AA) . Acetaldehyde $\cdot$ Cerium phosphate $(\mathrm{CeP})$

Komandur V. R. Chary

kvrchary@iict.res.in

1 Catalysis Division, Indian Institute of Chemical Technology, Hyderabad, India

\section{Introduction}

Biomass is a renewable resource which is an alternative substitution to the fossil fuels like petroleum, coal and natural gas. The interest in biomass conversion to chemicals has increased sharply during the last two decades from both academic and industrial point of view [1]. Lactic acid (2-hydroxy propanoic acid) is one of the well-recognized potential chemical produced from renewable biomass resources, which is an alternative feedstock for chemicals and materials [2]. Currently lactic acid (LA) can be produced via the fermentation of carbohydrates, glucose, sucrose [3, 4] and cellulose [5]. The presence of two reactive functional groups, i.e., a hydroxyl group and a carboxyl group makes lactic acid as an attractive feedstock for the production of wide range of useful chemicals such as acrylic acid, 1,2-propane diol, 2,3-pentane-dione, acetaldehyde, lactide, etc., via the dehydration, hydrogenation, condensation, decarboxylation/decarbonylation, esterification, respectively (Scheme 1). Acrylic acid (AA) is an important chemical intermediate in the manufacture of plastics, paint formulations, polymer solutions for coating applications, emulsion polymers, and paper coatings. Acrylic acid is also used as a chemical intermediate in the organic reactions [6, 7]. At present, acrylic acid is industrially produced by the gas-phase oxidation of propylene through a two-step process $[8,9]$.

Several patents have reported the dehydration of LA to AA over a variety of catalysts such as $\mathrm{CaSO}_{4} / \mathrm{NaSO}_{4}$, $\mathrm{Na}_{2} \mathrm{HPO}_{4}$ and $\mathrm{AlPO}_{4}$ [10-12]. Many of these reports confirm that selective dehydration LA to AA occurs over the catalysts possessing both the weak acidic and basic sites; whereas, strong acidic sites are responsible for the decarbonylation/decarboxylation to form acetaldehyde. The decarbonylation of LA to acetaldehyde was studied 
Scheme 1 Reactions for conversion of lactic acid into useful products

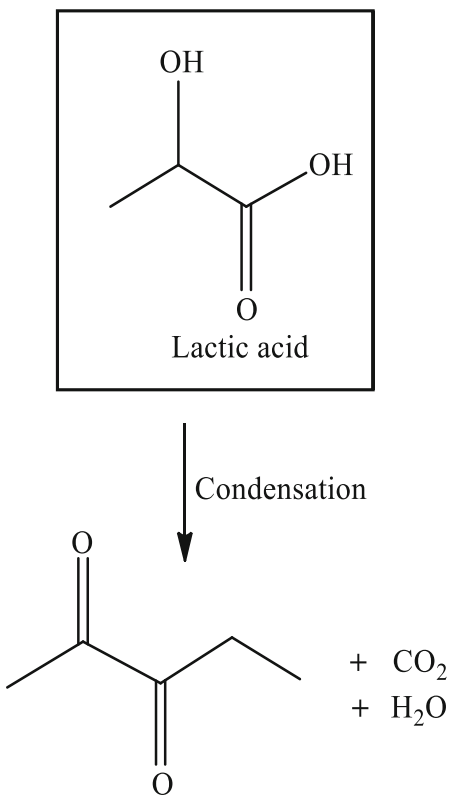

2,3-pentane-di-one
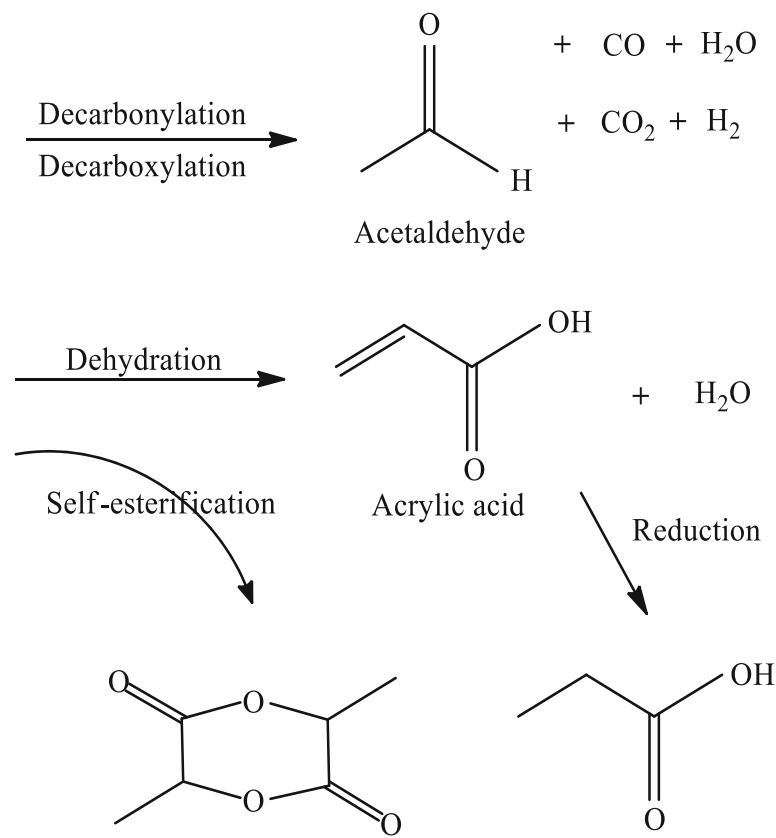

Di lactide

Propionic acid over $\mathrm{AlPO}_{4}$ and silica-supported heteropolyacids [13, 14] as majority of these materials have strong acidic sites. Recently, Tang et al. [15] also reported the synthesis of acetaldehyde from lactic acid over magnesium aluminate spinel.

Several authors reported in the literature recently on the dehydration of LA to AA over hydroxyapatite (HAp) catalysts [16-19] and Na-Y zeolites [20-23]. Ghantani et al. prepared various HAp catalysts by changing $\mathrm{Ca} / \mathrm{P}$ molar ratio at different $\mathrm{pHs}$ and reported a maximum of $60 \%$ selectivity towards AA [17]. Matsura et al. recently reported a high AA yield of about $80 \%$ [19]. Peng et al. reported approximately $68 \%$ AA selectivity over $\mathrm{Na}-\mathrm{Y}$ zeolites modified with potassium salts [20]. Most of this work has been reported on alkali and alkaline earth phosphates [24, 25], calcium phosphates (mostly hydroxyapatites) and modified zeolites [26, 27]. A few studies have been reported on other catalysts like barium sulphate $\left(\mathrm{BaSO}_{4}\right)$ [28], dibarium pyrophosphate [29], and silicasupported Na phosphates [30]. However, no work has been reported so far on rare earth metal phosphates as catalysts for the dehydration of lactic acid into acrylic acid.

In the recent past, rare earth metal phosphate materials have been gaining considerable attention as catalysts because of their unique properties such as high thermal phase stability, melting point and high surface area [31]. Moreover, these phosphates were used for various reactions like oxidative dehydrogenation of isobutane to isobutene, alkylation of phenol, dehydration of alcohol, etc., $[32,33]$. Basically, the rare earth oxides such as cerium oxide are basic in nature and introduction of phosphate groups leads to possesses both acidic and basic sites on the surface. As mentioned earlier, the acid-base functionalities of the catalysts play an important role in the dehydration of lactic acid into acrylic acid. Hence, our interest is to design and synthesize the materials with suitable acidic/basic sites for the dehydration of lactic acid by changing the amount of cerium and phosphorous in the catalysts.

In the present work, we report nano-crystalline cerium phosphate catalysts prepared with different $\mathrm{Ce} / \mathrm{P}$ mole ratios by changing the phosphate amount and keeping the $\mathrm{pH}$ constant at 4.5 and these catalysts have been screened for the dehydration of LA. Various reaction parameters like effect of temperature, effect of WHSV and time-on-stream analysis were carried out to optimize the reaction condition. The aim of this work is to understand the physicochemical characteristics of the prepared catalysts and to establish a relationship between catalysts acidity/basicity with the AA selectivity.

\section{Experimental}

\section{Catalyst synthesis}

Cerium phosphate catalysts were prepared by the method described by Ho et al. [34] with varying the molar ratio of $\mathrm{Ce} / \mathrm{P}$ from 0.5 to 3.0 . Briefly, the procedure involves dissolving $13.0266 \mathrm{~g}(0.3 \mathrm{~mol})$ of cerium nitrate hexahydrate (Aldrich $99 \%$ ) in $75 \mathrm{~mL}$ of Millipore water and stirred to 
get a clear solution. To this aqueous solution $3.418 \mathrm{~g}$ $(0.3 \mathrm{~mol}$, for $\mathrm{Ce} / \mathrm{P}$ mole ratio $=1.0)$ of $86 \%$ ortho phosphoric acid (Aldrich $86 \%$ aqueous solution) was added and the mixture was stirred for $1 \mathrm{~h}$. About $10 \%$ of aqueous ammonium hydroxide was used to precipitate out the cerium phosphate from the solution until the $\mathrm{pH}$ becomes 4.5. It was then allowed to age for $16 \mathrm{~h}$ at ambient temperature. The precipitate was filtered and washed with Millipore water and dried for $16 \mathrm{~h}$ at $80{ }^{\circ} \mathrm{C}$. Subsequently, the catalyst was made to fine powder followed by calcination for $3 \mathrm{~h}$ at $500{ }^{\circ} \mathrm{C}$ in air to make the final $\mathrm{CeP}$ catalysts. The samples were denoted as $\operatorname{CeP}(X)$, where $X=\mathrm{Ce} / \mathrm{P}$ mole ratio.

\section{Dehydration of lactic acid}

The catalytic dehydration of lactic acid was performed in a down flow fixed-bed reactor with $9 \mathrm{~mm}$ inner diameter and $300 \mathrm{~mm}$ length under atmospheric pressure. The cerium phosphate samples were pelletized and crushed into fine powder. This fine powder was meshed (20-40 mesh) to get a uniform size of the cerium phosphate sample. Approximately $300 \mathrm{mg}$ of the catalyst was diluted with glass beads and placed in between quartz wool. The top portion of the reactor was filled with molecular sieves which serve as pre-heating zone of the reaction feed. Prior to the reaction, the catalyst was preheated at $400{ }^{\circ} \mathrm{C}$ for $3 \mathrm{~h}$ under the flow of nitrogen $30 \mathrm{~mL} / \mathrm{min}$. The liquid feed containing $20 \mathrm{wt} \%$ aqueous lactic acid was fed using perfusor FM Infusion pump (B BRAUN, Germany) parallel to nitrogen flow of $30 \mathrm{~mL} / \mathrm{min}$. The products obtained were condensed using the cold trap, and analyzed by using Shimadzu GC 2014 equipped with DBwax column, $30 \mathrm{~m} \times 0.32 \mathrm{~mm}$. The obtained products were also confirmed by HP5973 quadruple GC-MSD system (HP-1MS capillary column, $15 \mathrm{~m} \times 0.25 \mathrm{~mm}$ ). As decarboxylation and decarbonylation reactions are main side reactions the formation of $\mathrm{CO}_{x}$ during the reaction $\left(\mathrm{CO}\right.$ and $\left.\mathrm{CO}_{2}\right)$ is inevitable. Thus, the non-condensable exit gas mixture was analyzed using Shimadzu GC 2014 (molecular sieve-5A column, $2 \mathrm{~m} \times 2 \mathrm{~mm}$, mesh-60/80) equipped with TCD detector. The results showed that the formed carbon oxides are not in a considerable range. However, the carbon deposited over the active sites in the spent samples was determined by using CHNS Analyzer-ELEMENTAR Vario microcube model. The carbon mass balance was calculated and it was found to be $>97 \%$. The experimental error in the evaluation of catalytic activities was less than $\pm 3 \%$, unless otherwise mentioned.

The LA conversion and product selectivity are defined according to the following calculations.

\section{LA conversion $(\%)$ \\ $=($ moles of LA consumed $/$ moles of LA in the feed $)$ $\times 100$}

Product selectivity (mole \%)

$=($ moles of carbon atoms in the specified product

/moles of carbon atoms in LA consumed)

$\times 100$

\section{Catalyst characterization}

X-ray powder diffraction patterns were obtained with a model D8 Diffractometer (Advance, Bruker, Germany), using nickel-filtered $\mathrm{Cu} \mathrm{K} \alpha$ radiation $(\lambda=1.5406 \AA)$ at $40 \mathrm{kV}$ and $30 \mathrm{~mA}$. The measurements were recorded in steps of $0.012^{\circ}$ with a count time of $13.6 \mathrm{~s}$. in the $2 \theta$ range of $2^{\circ}-65^{\circ}$. Identification of the phase and planes were made with the help of International Centre for Diffraction Data (ICDD) files. The FT-IR spectra of the catalysts were recorded in a range of $400-4000 \mathrm{~cm}^{-1}$ on the IR spectrometer (Model: GC-FT-IR Nicolet 670) using KBr disc method under ambient condition.

The morphological features of the catalysts were monitored using a JEOL JEM 2000EXII transmission electron microscope, operating between 160 and $180 \mathrm{kV}$. The specimens were prepared by dispersing the samples in ethanol for 30 min using an ultrasonic bath and evaporating a drop of resultant suspension was placed on a hollow copper grid coated with a carbon film made in the laboratory.

The morphology of the samples was investigated by using scanning electron microscopy (Model: EVO 18 Carl Zeiss). Prior to analysis, the sample was sprinkled on a $1-\mathrm{cm}$ stub sticked with a double-sided carbon tape and it is sputter coated in a sputter chamber with gold target to avoid charging and the stub is fixed in the SEM instrument.

The surface areas of the catalyst samples were obtained from $\mathrm{N}_{2}$ adsorption data acquired by using Autosorb-1C instrument (Quantachrome instruments, USA) at $-196{ }^{\circ} \mathrm{C}$. Initially the samples were out gassed at $300{ }^{\circ} \mathrm{C}$ to ensure a clean surface prior to construction of adsorption isotherm. A cross-sectional area of $0.164 \mathrm{~nm}^{2}$ of the $\mathrm{N}_{2}$ molecule was assumed in the calculations of the surface areas using the multipoint BET method.

TPD experiments were also conducted on AutoChem 2910 (Micromeritics, USA) instrument. In a typical experiment for TPD studies, $100 \mathrm{mg}$ of oven-dried sample was taken in a U-shaped quartz sample tube. The catalyst was mounted on a quartz wool plug. Prior to TPD studies, the sample was pretreated by passing high-purity $(99.995 \%)$ helium $\left(50 \mathrm{~mL} \mathrm{~min}^{-1}\right)$ at $200{ }^{\circ} \mathrm{C}$ for $1 \mathrm{~h}$. After pretreatment, the sample was saturated with $10 \% \mathrm{NH}_{3} / \mathrm{He}$ 
at $80{ }^{\circ} \mathrm{C}$ for $30 \mathrm{~min}$ and subsequently flushed with He flow $\left(50 \mathrm{~mL} \mathrm{~min}{ }^{-1}\right)$ at $100{ }^{\circ} \mathrm{C}$ for $1 \mathrm{~h}$ to remove physisorbed ammonia. TPD analysis was carried out from ambient temperature to $650{ }^{\circ} \mathrm{C}$ at a heating rate of $10{ }^{\circ} \mathrm{C} \mathrm{min}{ }^{-1}$. The amount of $\mathrm{NH}_{3}$ desorbed was calculated using GRAMS/32 software. The $\mathrm{CO}_{2}$-TPD analysis was also done as same above by using a mixture of $10 \% \mathrm{CO}_{2}-\mathrm{He}$ $\left(50 \mathrm{~mL} \mathrm{~min}^{-1}\right)$. Thermogravimetric analysis was carried out using TGA-Q500 for calcined and spent $\mathrm{CeP}(2.5)$ catalysts at a heating rate of $10{ }^{\circ} \mathrm{C} / \mathrm{min}$ from 25 to $800{ }^{\circ} \mathrm{C}$ in the presence of air flow.

The ex situ experiments of FT-IR spectra of pyridineadsorbed samples were carried out to find out the Brønsted and Lewis acid sites. Pyridine was adsorbed on the activated catalysts at $120{ }^{\circ} \mathrm{C}$ until saturation. Prior to adsorption experiments, the catalysts were activated in $\mathrm{N}_{2}$ flow at $200{ }^{\circ} \mathrm{C}$ for $1 \mathrm{~h}$ to remove moisture from the samples. After such activation the samples were cooled to room temperature. The IR spectra were recorded using an IR (Model: GC-FT-IR Nicolet 670) spectrometer by $\mathrm{KBr}$ disc method under ambient conditions.

\section{Results and discussion}

\section{Characterization results}

To understand the effect of Ce/P mole ratio on the catalyst structure and to establish the correlation with catalytic activity, the catalysts were characterized by various spectroscopic and adsorption techniques. X-ray diffraction
(XRD) studies were recorded in the $2 \theta$ range $2^{\circ}-65^{\circ}$ to investigate the structure of cerium phosphate samples calcined at $500{ }^{\circ} \mathrm{C}$. The well-defined peaks corresponding to reflections of the $\mathrm{CeP}$ and cerium oxide $\left(\mathrm{CeO}_{2}\right)$ catalysts are shown in Fig. 1. The peaks corresponding to all $\mathrm{CeP}$ samples were shown similar pattern which is different from the diffractogram of $\mathrm{CeO}_{2}$. The X-ray diffractograms (in the range $2 \theta=2^{\circ}-65^{\circ}$ ) of the $\mathrm{CeO}_{2}$ show the presence of (111), (200), (220) and (311) reflection planes corresponding to a face centered cubic structure of cerium oxide $\left(\mathrm{CeO}_{2}\right)$. The lattice parameters calculated from this pattern ( $a=b=c=5.42 \AA$ ) are in accordance with the reported values [ICDD PDF NO. 04-0593] [30, 34, 35]. The peaks for $\mathrm{CeP}$ catalysts were identified as hexagonal cerium phosphate $\left(\mathrm{CePO}_{4}\right)$ [ICDD PDF No. 04-0632]. The peak widths indicate that all the samples are crystalline in nature. The crystallite sizes were estimated using Scherrer equation, which show a small decrease of crystallite size ranging from 7.14 to $5.28 \mathrm{~nm}$ with increasing of $\mathrm{Ce} / \mathrm{P}$ mole ratio (Table 1), while the cerium oxide shows a crystallite size $(10.2 \mathrm{~nm})$ more than the cerium phosphate samples.

The FT-IR studies were conducted for $\mathrm{CeP}$ and $\mathrm{CeO}_{2}$ catalysts and the results are shown in Fig. 2. The results suggest that all the catalysts exhibit a broad band in the region $3450 \mathrm{~cm}^{-1}$ which was attributed to asymmetric and symmetric stretching vibration of $\mathrm{O}-\mathrm{H}$ due to residual water and presence of structural hydroxyl groups. A medium intense band noticed at $1650 \mathrm{~cm}^{-1}$ was attributed to aquo $\mathrm{H}-\mathrm{O}-\mathrm{H}$ bending [38]. The bands at 1050, 620 and $542 \mathrm{~cm}^{-1}$ were attributed to $\mathrm{P}=\mathrm{O}$ stretching, $\mathrm{O}=\mathrm{P}-\mathrm{O}$ and $\mathrm{O}-\mathrm{P}-\mathrm{O}$ bending modes, respectively. These bands indicate
Fig. $1 \mathrm{X}$-ray diffraction patterns of $\mathrm{CeP}$ and $\mathrm{CeO}_{2}$ catalysts

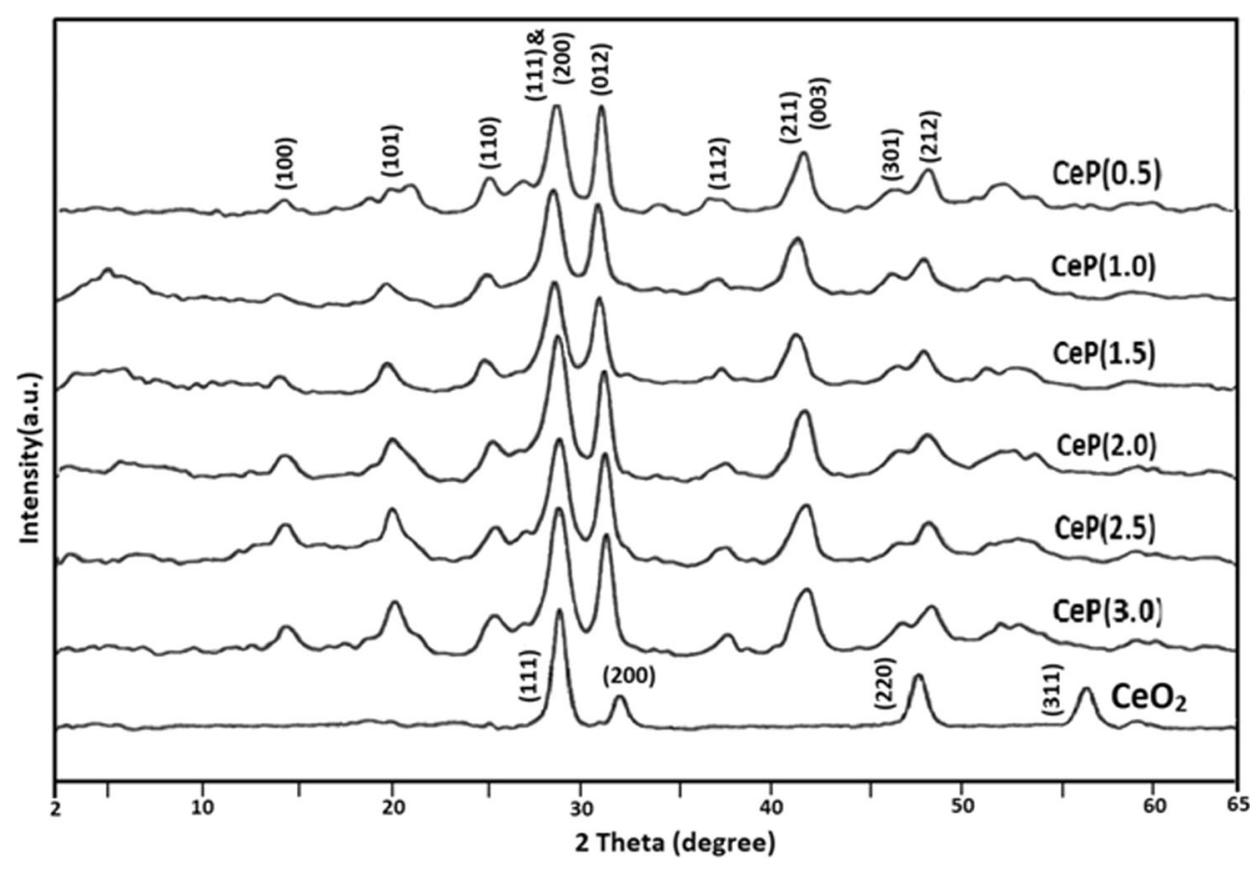


Table 1 Crystallite and particle sizes of CeP catalysts using XRD and TEM analysis

\begin{tabular}{llll}
\hline Catalyst & Ce/P ratio & Crystallite size from XRD $(\mathrm{nm})$ & Particle size/length $\times$ width observed from TEM $(\mathrm{nm})$ \\
\hline $\mathrm{CeP}(0.5)$ & 0.47 & 7.14 & $(70-90) \times(9.3-11.2)$ \\
$\mathrm{CeP}(1.0)$ & 0.92 & 6.52 & $(65-80) \times(7.5-9.2)$ \\
$\mathrm{CeP}(1.5)$ & 1.55 & 6.12 & $(62-75) \times(6.5-8.0)$ \\
$\mathrm{CeP}(2.0)$ & 2.11 & 5.91 & $(50-64) \times(5.8-6.9)$ \\
$\mathrm{CeP}(2.5)$ & 2.45 & 5.36 & $(45-55) \times(5.5-6.5)$ \\
$\mathrm{CeP}(3.0)$ & 2.87 & 5.28 & $(42-50) \times(5.0-6.2)$ \\
\hline
\end{tabular}

a Values obtained from EDX analysis

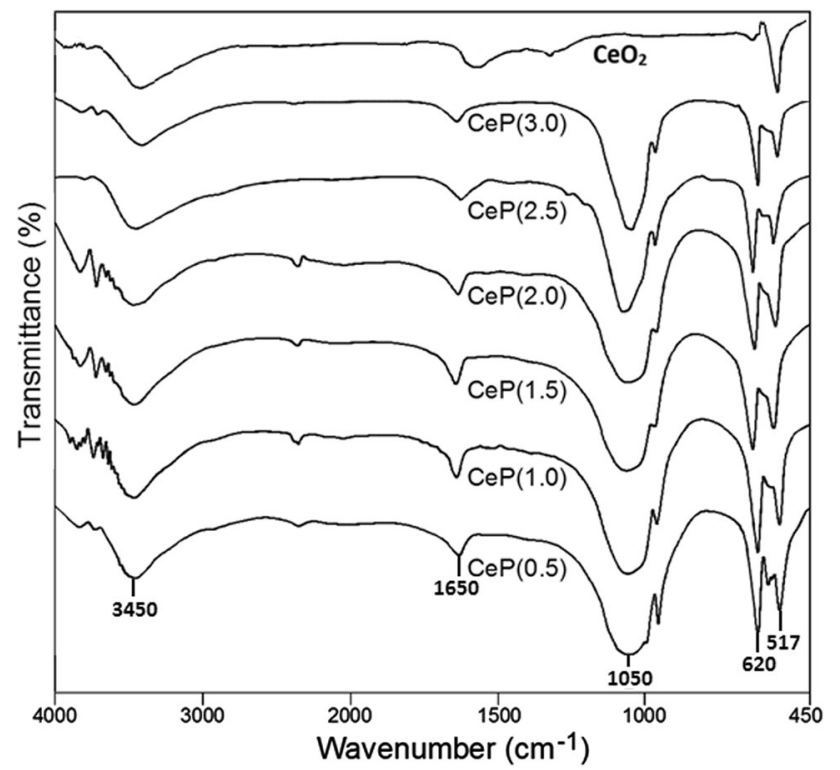

Fig. 2 FT-IR spectra for $\mathrm{CeP}$ and $\mathrm{CeO}_{2}$ catalysts

the presence of structural hydroxyl groups and phosphate groups in the synthesized materials [36, 37]; whereas, there is only a similar sharp and intense peak noticed at $517 \mathrm{~cm}^{-1}$ in both $\mathrm{CeO}_{2}$ and $\mathrm{CeP}$ catalysts, which is attributed to metal-oxygen (Ce-O) stretching vibrations [39].

The TEM images of the cerium phosphate catalysts with various $\mathrm{Ce} / \mathrm{P}$ ratios are shown in Fig. 3 and the particle sizes calculated from TEM images are presented in Table 1. TEM analysis revealed that the particle sizes ranged between $(70-90 \mathrm{~nm}) \times(9.3-11.2 \mathrm{~nm})$ and $(42-50 \mathrm{~nm}) \times(5.0-6.2 \mathrm{~nm})$ for $\mathrm{CeP}(0.5-3.0)$ samples. These particle sizes are well in agreement with the crystallite size calculated from the XRD broadening method using the Scherrer equation (Table 1). Furthermore, TEM results clearly suggest that the formation of rod-shaped particles of single crystal.

The SEM images of the calcined and spent cerium phosphate $(\mathrm{CeP})$ catalysts with $\mathrm{Ce} / \mathrm{P}$ ratio of 2.5 are shown in Fig. 4. The SEM images of fresh and spent $\mathrm{CeP}(2.5) \mathrm{did}$ not show any peculiar shapes of cerium phosphate particles. The SEM-EDS analysis was used to find out the Ce/P ratio present in the synthesized cerium phosphate catalysts and the results are illustrated in Table 1. The EDS analysis reveals that the $\mathrm{Ce} / \mathrm{P}$ ratio of as-synthesized sample was almost close to the theoretically calculated values.

The total acidity of cerium phosphate catalysts was measured by $\mathrm{NH}_{3}$-TPD method and the total basicity was measured by $\mathrm{CO}_{2}$-TPD methods. $\mathrm{NH}_{3}$ and $\mathrm{CO}_{2}$-TPD profiles of all CeP catalysts are shown in Fig. 5a, b. Both $\mathrm{NH}_{3}$ and $\mathrm{CO}_{2}$-TPD profiles exhibit similar pattern of acidity and basicity profiles. All the prepared catalysts exhibit mainly weakly acidic and weakly basic sites with desorption temperatures ranging between 100 and $230{ }^{\circ} \mathrm{C}$. Their temperatures of maxima of desorption $\left(T_{\max }\right)$ were only varied from 155 to $175{ }^{\circ} \mathrm{C}$; whereas, the $\mathrm{NH}_{3}$-TPD profiles of $\mathrm{CeP}(0.5), \mathrm{CeP}(1.0)$ and $\mathrm{CeP}(1.5)$ catalysts are showing a little broad peak between 260 and $320{ }^{\circ} \mathrm{C}$ which correspond to moderate acidic sites. The total acidity and basicity values are presented in Table 2 . The results of Table 2 also present the density of surface acidic sites (surface acidity) and basic sites (surface basicity), which are obtained by normalizing to the sample surface area and measured from the $\mathrm{NH}_{3}$ - and $\mathrm{CO}_{2}$-TPD peaks. Furthermore, the acid-base balance (acid-to-base atomic balance) was calculated by the ratio of total amount of acidity to total amount of basicity.

The ex situ-adsorbed pyridine FT-IR analysis was carried out to differentiate Bronsted and Lewis acidic sites and results are presented in Fig. 6. All the samples exhibited three IR bands in the region of 1445, 1490, $1545 \mathrm{~cm}^{-1}$ that are due to the Lewis (L), Bronsted and Lewis $(B+L)$, Bronsted (B) acidic sites, respectively. It is interesting to note that the intensity of these IR bands varies by changing the $\mathrm{Ce} / \mathrm{P}$ ratio of the cerium phosphate samples and the intensity of the band is proportional to the concentration of acid sites. The IR spectra of the samples with high $\mathrm{Ce} / \mathrm{P}$ ratio [(CeP-(2.5 and 3.0)] exhibit a band at $1445 \mathrm{~cm}^{-1}$ related to Lewis acidic sites and the intensity of this band decreased with the decrease of $\mathrm{Ce} / \mathrm{P}$ ratio of cerium phosphate samples. Interestingly, the 
Fig. 3 TEM images of a $\mathrm{CeP}(2.5): 50 \mathrm{~nm}$, b $\mathrm{CeP}(2.5)$ : $100 \mathrm{~nm}, \mathbf{c} \operatorname{CeP}(1.0): 100 \mathrm{~nm}$, d $\mathrm{CeP}(3.0): 50 \mathrm{~nm}$
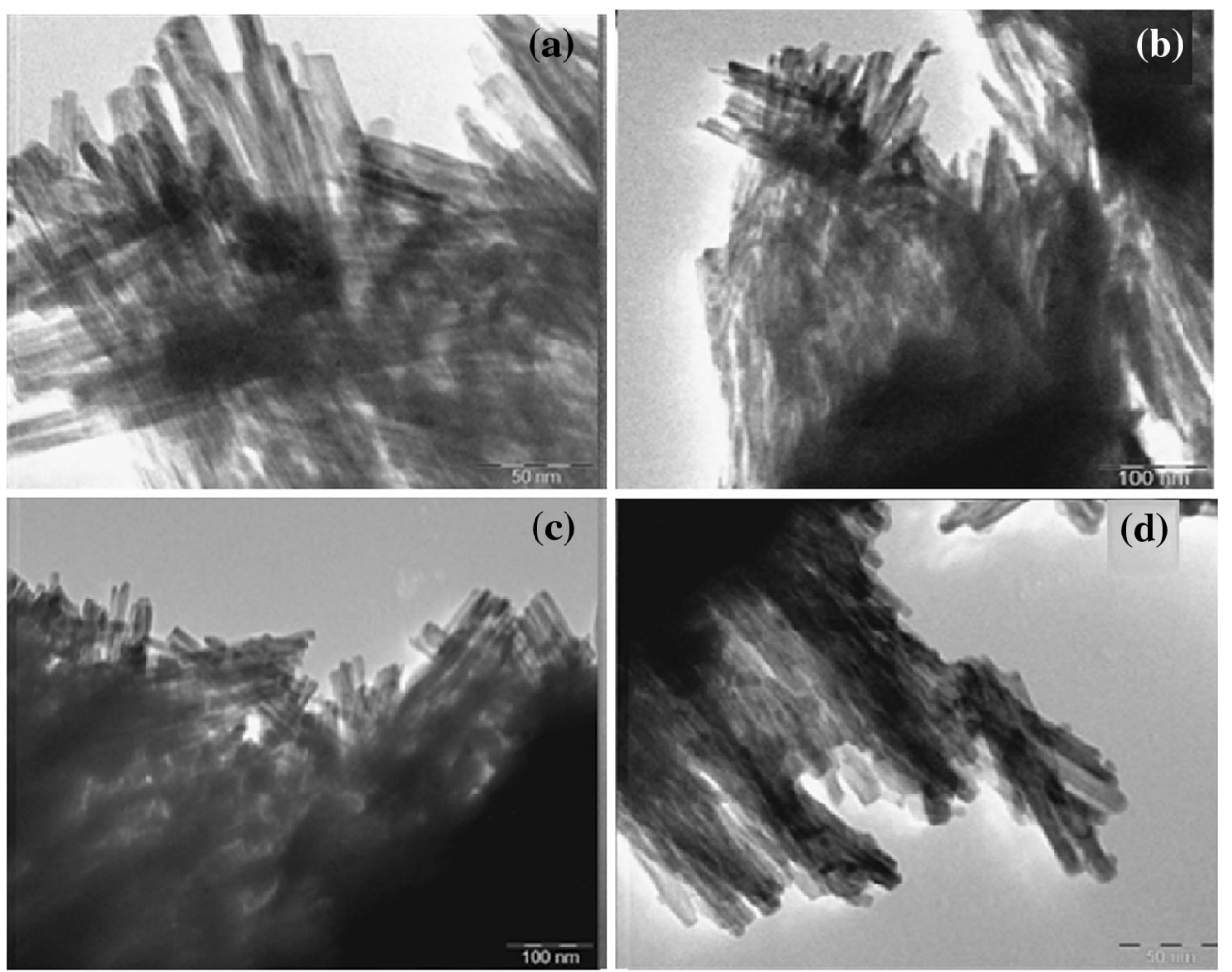

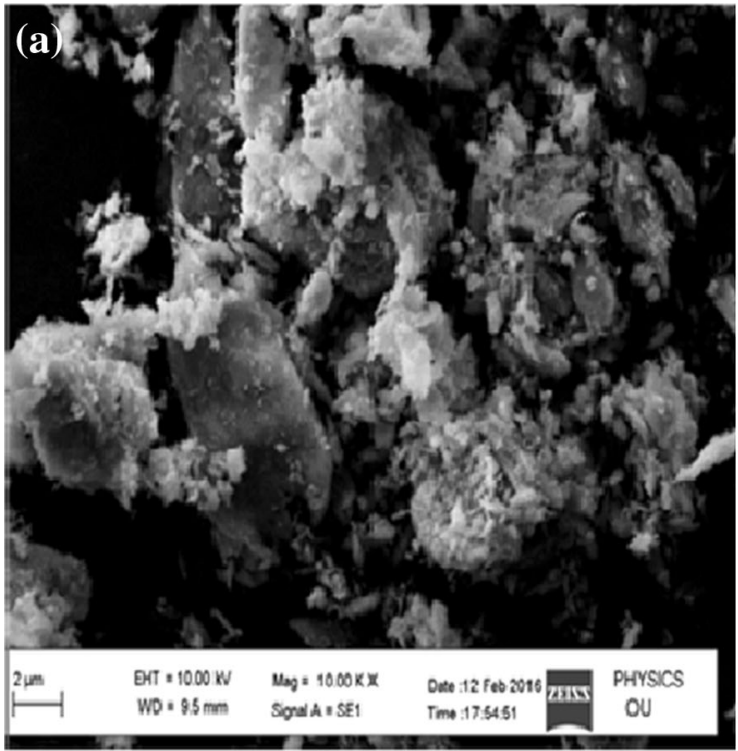

Fig. 4 SEM images of fresh and spent $\operatorname{CeP}(2.5)$ samples

intensity of the IR bands at $1495 \mathrm{~cm}^{-1}, 1540 \mathrm{~cm}^{-1}$ attributed to the total acidic sites and Bronsted acidic sites increased with the decrease of $\mathrm{Ce} / \mathrm{P}$ ratio of cerium phosphate samples. This is due to the exposure of more amount of surface $\mathrm{P}-\mathrm{OH}$ of phosphate group in the cerium phosphate sample. These findings are in good agreement with the results obtained from ammonia TPD analysis and SEM-EDS analysis.

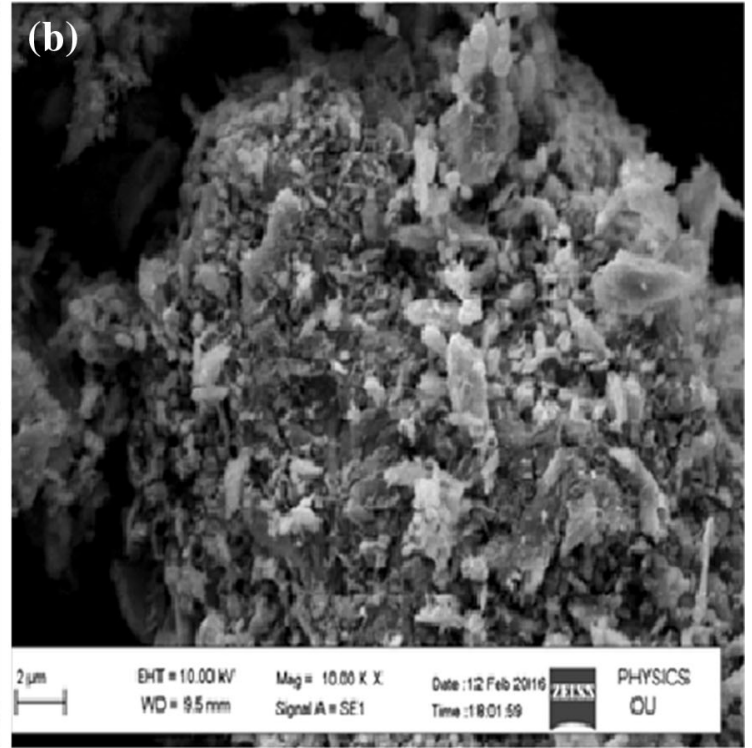

\section{Catalytic performance}

\section{Effect of catalyst: Ce/P mole ratio}

The catalytic performance of cerium phosphate catalysts prepared with different mole ratios was tested for the dehydration of lactic acid (LA) to acrylic acid (AA) and the results are presented in Table 3. The selective 

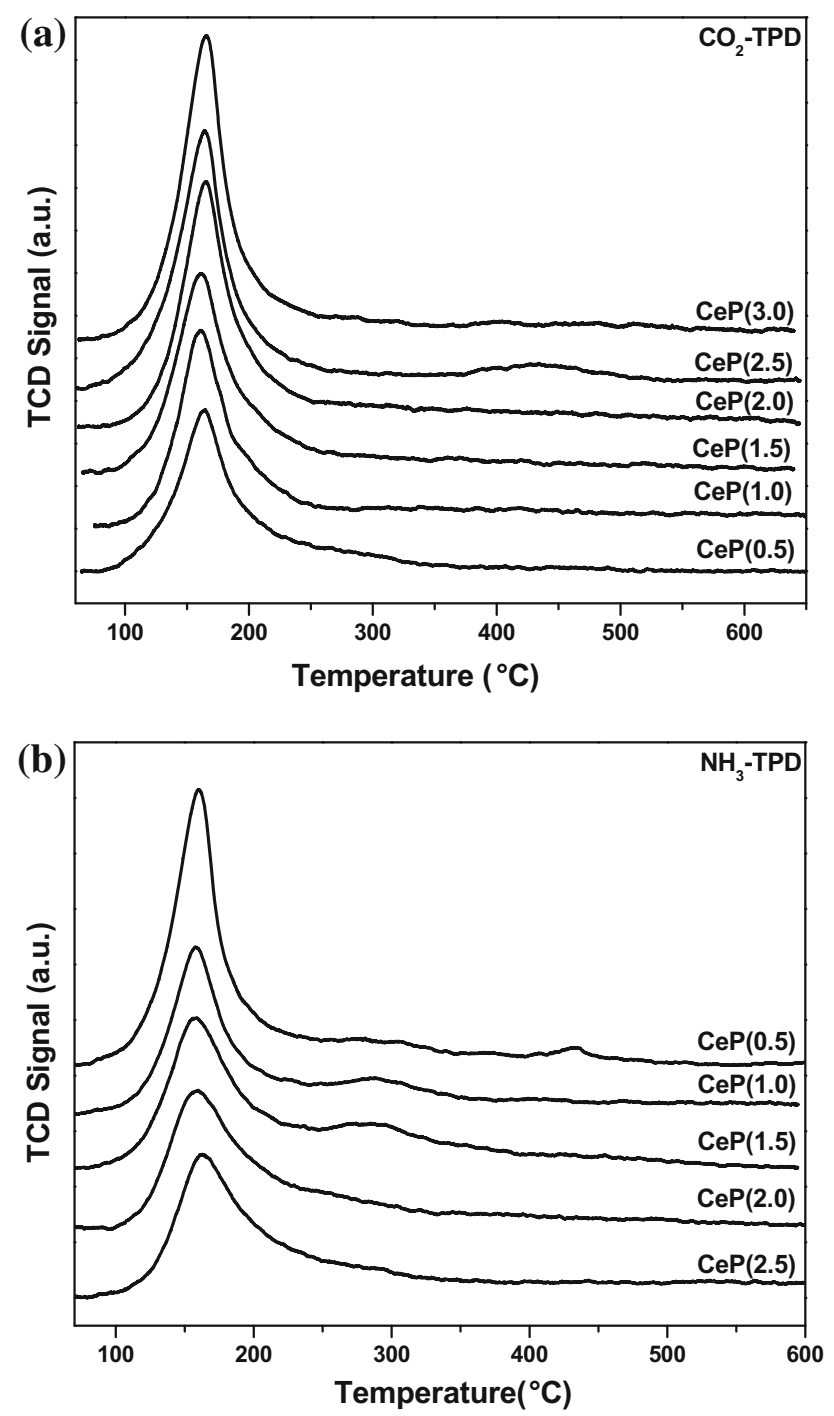

Fig. 5 a $\mathrm{CO}_{2}$-TPD profiles of $\mathrm{CeP}$ catalysts. $\mathbf{b} \mathrm{NH}_{3}$-TPD profiles of CeP catalysts

formation of AA through dehydration of LA is challenging task with competing formation of side products. The surface acidity and basicity of the catalyst play a decisive role in the product selectivity. If the catalyst

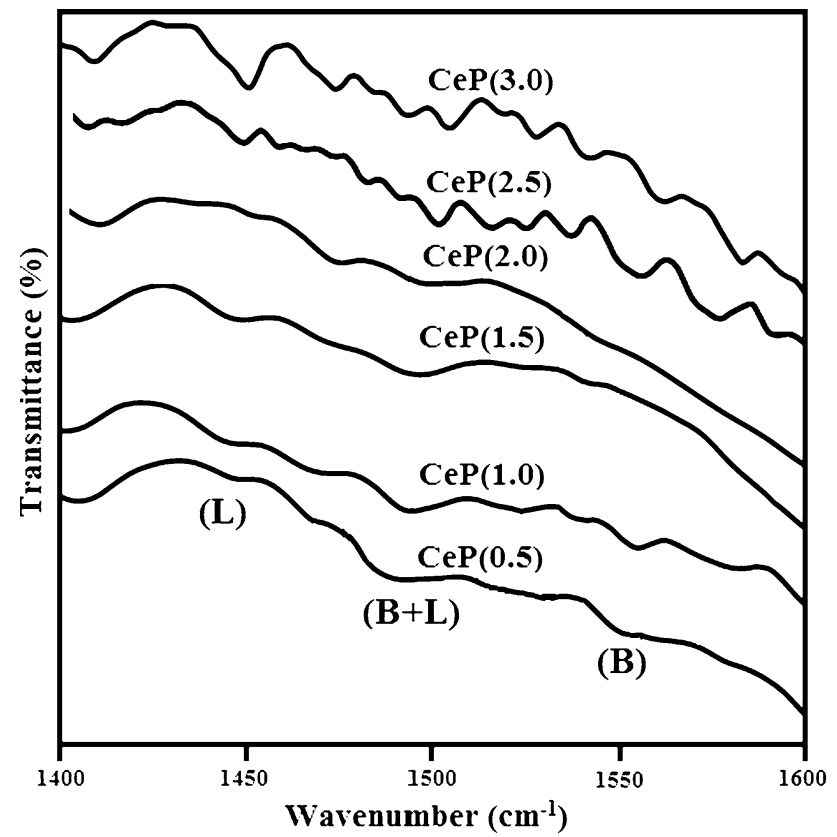

Fig. 6 Ex situ adsorbed pyridine FT-IR analysis

possesses more acidic sites it favors the decarbonylation/ decarboxylation to produce acetaldehyde. In the present study, $\mathrm{CeP}(0.5)$ possesses more number of acidic sites as evidenced from $\mathrm{NH}_{3}$-TPD and produces acetaldehyde rather than AA. It is clear from the Table 3 that the decrease in acidity favors the increase of selectivity to AA up to $\mathrm{CeP}(2.5)$ and decreases selectivity of AA at higher $\mathrm{CeP}$ ratio in the catalyst. This means that decrease in the acidic sites density could control some of side reactions such as acetaldehyde formation leading to an increase of the selectivity towards AA. For $\mathrm{CeP}(3.0)$ the increased basic sites density favors the formation of propionic acid and other side products. Hence, acid-base balance factor (surface acidity-to-basicity ratio) is an important property of the catalysts which determines the product selectivity. The maximum AA selectivity was achieved with $\mathrm{CeP}(2.5)$ with the acid-base factor 0.56.

Table 2 BET surface area, acid and base structural properties of CeP catalysts

\begin{tabular}{|c|c|c|c|c|c|c|}
\hline Catalyst & $\begin{array}{l}S_{\mathrm{BET}} \\
\left(\mathrm{m}^{2} / \mathrm{g}\right)\end{array}$ & $\begin{array}{l}\text { Total amount } \\
\text { of acid }(\mu \mathrm{mol} / \mathrm{g})\end{array}$ & $\begin{array}{l}\text { Total amount } \\
\text { of base }(\mu \mathrm{mol} / \mathrm{g})\end{array}$ & $\begin{array}{l}\text { Acidity density } \\
\left(\mu \mathrm{mol} / \mathrm{m}^{2}\right)\end{array}$ & $\begin{array}{l}\text { Basicity density } \\
\left(\mu \mathrm{mol} / \mathrm{m}^{2}\right)\end{array}$ & $\begin{array}{l}\text { Acid-base } \\
\text { balance }\end{array}$ \\
\hline $\mathrm{CeP}(0.5)$ & 38.64 & 653 & 475 & 16.90 & 12.29 & 1.37 \\
\hline $\mathrm{CeP}(1.0)$ & 50.88 & 532 & 493 & 10.46 & 9.69 & 1.08 \\
\hline $\mathrm{CeP}(1.5)$ & 31.61 & 424 & 564 & 13.41 & 17.84 & 0.75 \\
\hline $\mathrm{CeP}(2.0)$ & 32.02 & 364 & 595 & 11.36 & 18.58 & 0.61 \\
\hline $\mathrm{CeP}(2.5)$ & 58.05 & 347 & 622 & 5.97 & 10.71 & 0.56 \\
\hline $\mathrm{CeP}(3.0)$ & 50.19 & 318 & 681 & 6.33 & 13.57 & 0.47 \\
\hline
\end{tabular}


Table 3 Results for LA dehydration over CeP catalysts

\begin{tabular}{|c|c|c|c|c|c|c|}
\hline \multirow[t]{2}{*}{ Catalyst } & \multirow[t]{2}{*}{ Conversion of LA (\%) } & \multicolumn{5}{|l|}{ Selectivity (\%) } \\
\hline & & Acetaldehyde & Acrylic acid & Propionic acid & Acetic acid & Others \\
\hline $\mathrm{CeP}(0.5)$ & 99.7 & 55.1 & 32.7 & 3.4 & 1.7 & 7.1 \\
\hline $\mathrm{CeP}(1.0)$ & 99.6 & 33.2 & 55.2 & 5.4 & 1.9 & 4.3 \\
\hline $\mathrm{CeP}(1.5)$ & 99.5 & 28.1 & 59.6 & 6 & 1.5 & 4.8 \\
\hline $\mathrm{CeP}(2.0)$ & 99.6 & 24.6 & 62.5 & 6.6 & 1.1 & 5.2 \\
\hline $\mathrm{CeP}(2.5)$ & 99.5 & 21 & 64.2 & 7.4 & 0.7 & 6.7 \\
\hline $\mathrm{CeP}(3.0)$ & 99.7 & 18.2 & 56.4 & 15.7 & 0.6 & 9.1 \\
\hline
\end{tabular}

Reaction conditions: reaction feed $=20 \mathrm{wt} \% \mathrm{LA}$, feed flow $=0.5 \mathrm{~mL} / \mathrm{h}, \mathrm{N}_{2}$ flow $=30 \mathrm{~mL} / \mathrm{h}$, catalyst weight $=300 \mathrm{mg}$, reaction temperature $=380{ }^{\circ} \mathrm{C}$ and WHSV $=1.74 \mathrm{~h}^{-1}$. Others includes 2,3-pentane dione, hydroxyacetone and some unidentified products

\section{Effect of reaction temperature}

It is well established that the effect of reaction temperature influences the product selectivity in the dehydration reactions. The influence of temperature was investigated on the catalytic performance of $\mathrm{CeP}(2.5)$ catalyst ranging $320-400{ }^{\circ} \mathrm{C}$. The reaction temperature not only affects the conversion of LA, but also AA selectivity, suggesting that this reaction was sensitive to temperature. When the reaction temperature changes from 320 to $380{ }^{\circ} \mathrm{C}$, the conversion of LA was increased from 85 to $>99.5 \%$ and the selectivity towards AA also increased from 38 to $64.2 \%$. When the temperature was increased to $400{ }^{\circ} \mathrm{C}$, a marginal decrease of AA selectivity was observed from 64.2 to $57 \%$, but the LA conversion did not change appreciably at $\sim 99 \%$. The products distribution and conversions at different reaction temperatures are shown in Fig. 7.

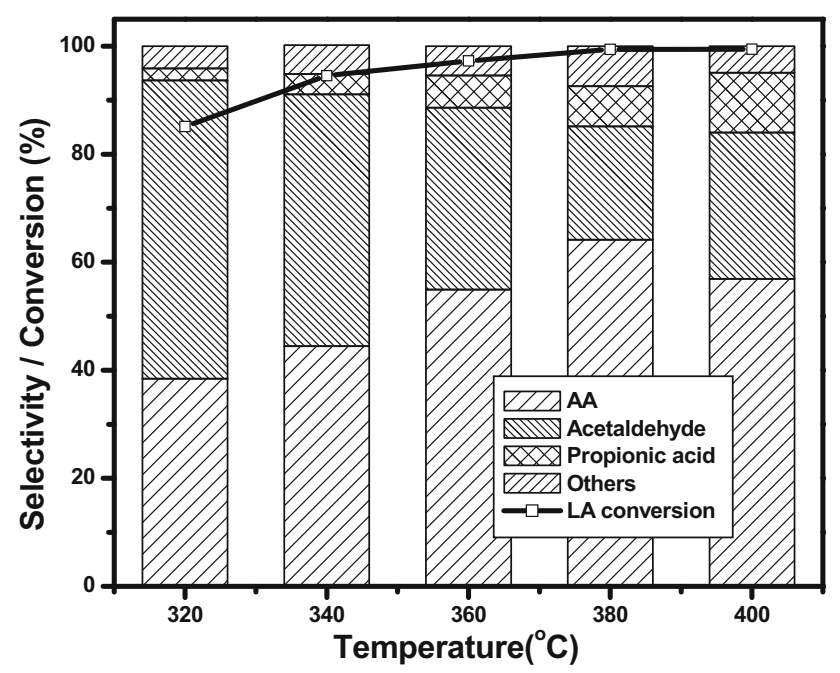

Fig. 7 Effect of temperature on LA conversion and product selectivity. Reaction conditions at different temperatures: reaction feed $=20 \mathrm{wt} \% \mathrm{LA}$, feed flow $=0.5 \mathrm{~mL} / \mathrm{h}, \mathrm{N}_{2}$ flow $=30 \mathrm{~mL} / \mathrm{h}$, catalyst $\mathrm{CeP}(2.5)=300 \mathrm{mg}$ and WHSV $=1.74 \mathrm{~h}^{-1}$

\section{Effect of WHSV}

The effect of weight hour space velocity (WHSV) was employed for LA dehydration with different flow rates of reaction feed $(20 \mathrm{wt} \%$ LA solution, density $=1.0424 \mathrm{~g} /$ $\mathrm{mL})$ from $0.5 \mathrm{~mL} / \mathrm{h}\left(\mathrm{WHSV}=1.74 \mathrm{~h}^{-1}\right.$ ) to $2.0 \mathrm{~mL} / \mathrm{h}$ (WHSV $=6.95 \mathrm{~h}^{-1}$ ) by keeping weight of the catalyst constant. It was observed that maximum LA conversion of $99.5 \%$ and AA selectivity of $64.2 \%$ was achieved when WHSV $=1.74 \mathrm{~h}^{-1}$; whereas, further increase of WHSV from 1.74 to $6.95 \mathrm{~h}^{-1}$ both the LA conversion and AA selectivity was decreased to 92.5 and $50 \%$, respectively. WHSV values were calculated using the following formulae and the results are presented in Fig. 8.

WHSV $=$ mass of flow $(\mathrm{g} / \mathrm{h}) /$ weight of the catalyst $(\mathrm{g})$,

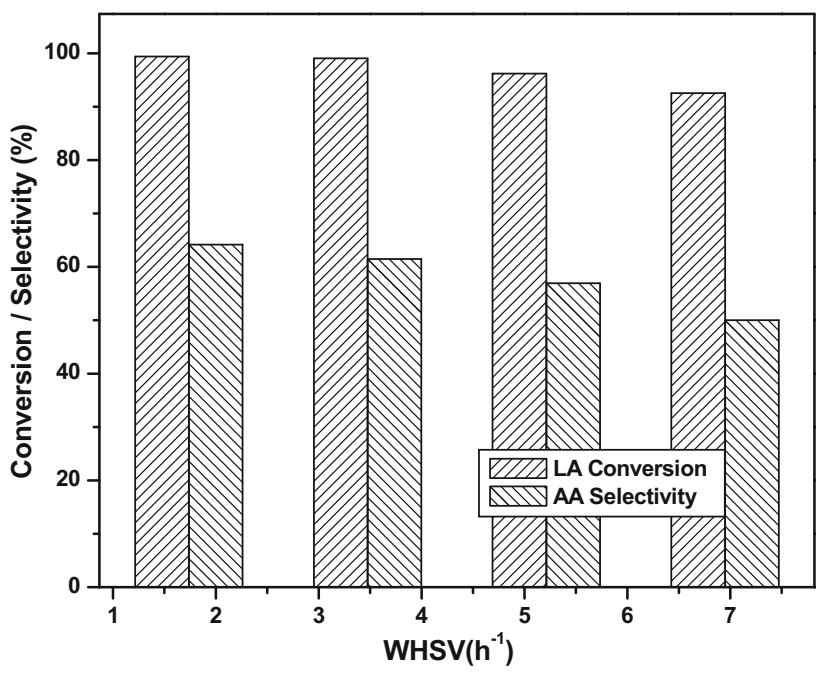

Fig. 8 Effect of WHSV on the catalytic performance of $\mathrm{CeP}(2.5)$. Reaction conditions at different WHSV: reaction feed $=20 \mathrm{wt} \% \mathrm{LA}$, $\mathrm{N}_{2}$ flow $=30 \mathrm{~mL} / \mathrm{h}$, catalyst $\mathrm{CeP}(2.5)=300 \mathrm{mg}$, reaction temperature $=380{ }^{\circ} \mathrm{C}$ 
where mass of flow $=$ feed flow rate $(\mathrm{mL} / \mathrm{h}) \times$ density of feed flow $(\mathrm{g} / \mathrm{mL})$.

\section{Time on stream}

The catalytic performance with time on stream has been investigated to find the stability of CeP catalysts. Figure 9 shows the results of $\mathrm{CeP}(2.5)$ catalyst during the dehydration of LA over a period of $20 \mathrm{~h}$ time on stream (TOS) at $380{ }^{\circ} \mathrm{C}$ and WHSV $=1.74 \mathrm{~h}^{-1}$. During the initial hours, it remained above $97 \%$ conversion of LA and reaches up to $99.5 \%$ at $6 \mathrm{~h}$ and remains unchanged until $16 \mathrm{~h}$ of TOS. On the other hand AA selectivity was found initially around $55 \%$ and reached maximum up to $64.2 \%$ and it remained unchanged for $10 \mathrm{~h}$ during the time on stream. However, a slight decrease of AA selectivity was noticed when the LA conversion was decreased up to $80 \%$ after $16 \mathrm{~h}$ of TOS.

\section{Deactivation studies}

During the catalytic transformation of bio-based molecules, the catalyst deactivation is a common and serious problem due to poor thermal stability of the reactants. Catalyst deactivation was studied for $\mathrm{CeP}(2.5)$ catalysts before (calcined) and after (spent) the reaction. The examination of the results of XRD, FT-IR, TGA and CHNS analysis of spent catalyst reveals that carbonaceous species is formed. The carbon deposits on the spent catalyst might be in amorphous nature since the XRD analysis of spent $\mathrm{CeP}(2.5)$ catalyst did not show any reflections (Fig. 10a)

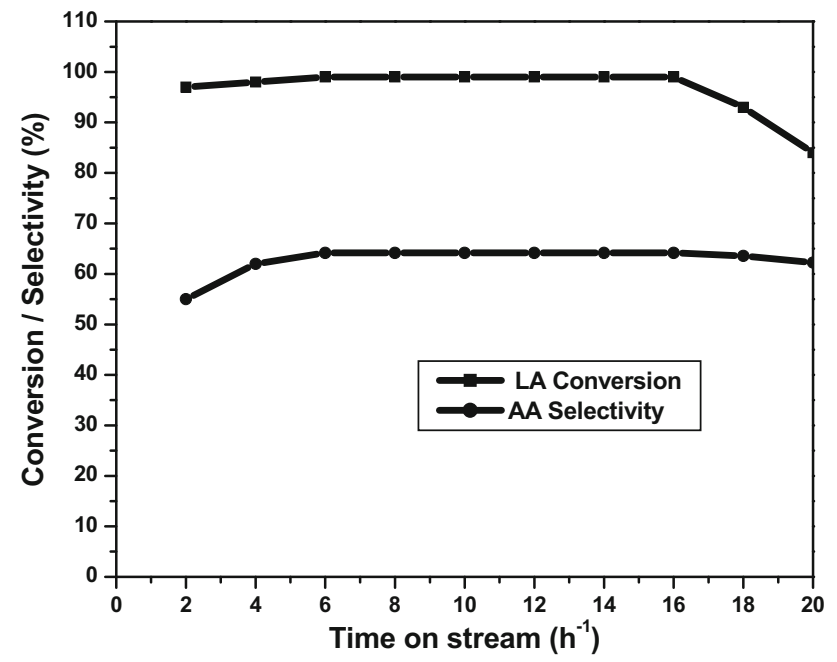

Fig. 9 LA conversion and AA selectivity with time on stream over $\mathrm{CeP}(2.5)$. Reaction conditions: reaction feed $=20 \mathrm{wt} \% \mathrm{LA}$, feed flow $=0.5 \mathrm{~mL} / \mathrm{h}, \mathrm{N}_{2}$ flow $=30 \mathrm{~mL} / \mathrm{h}$, catalyst weight $=300 \mathrm{mg}$, reaction temperature $=380{ }^{\circ} \mathrm{C}$ and $\mathrm{WHSV}=1.74 \mathrm{~h}^{-1}$ corresponding to crystalline carbon deposits. However, FTIR studies of the spent catalyst have shown two additional peaks at 2925 and $1720 \mathrm{~cm}^{-1}$ (Fig. 10b) compared to the FT-IR spectra of the calcined $\mathrm{CeP}(2.5)$, which correspond to $\mathrm{C}=\mathrm{O}$ stretching and $\mathrm{C}-\mathrm{H}$ stretching frequencies. These are formed probably due to the formation of lactates and acrylates from LA, AA and other residing products [17].

TGA studies of calcined $\operatorname{CeP}(2.5)$ catalyst have further shown only the weight loss of weakly adsorbed water molecules between 120 and $250{ }^{\circ} \mathrm{C}$; whereas, spent $\mathrm{CeP}(2.5)$ catalyst showed two weight loss peaks. The first weight loss peak between 250 and $350{ }^{\circ} \mathrm{C}$ was attributed to hydrated water molecules and the second weight loss ( 9-10\%) peak between 450 and $550{ }^{\circ} \mathrm{C}$ was attributed to the presence of carbonaceous species deposited on the catalyst surface (Fig. 11). Further the presence of carbon was also confirmed from the CHNS analysis of the spent catalyst (Table 4). From the above study, it is confirmed
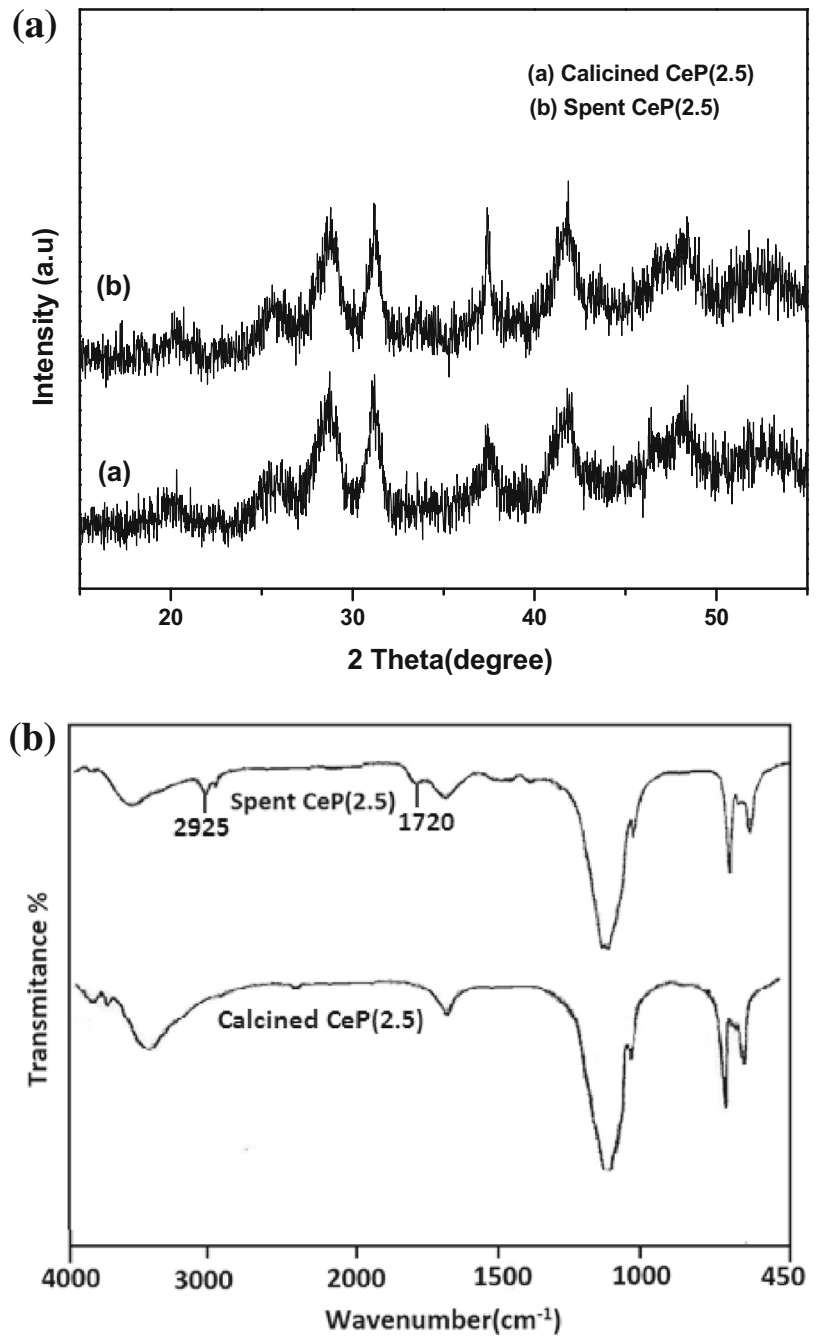

Fig. 10 Characterization results for calcined and spent $\operatorname{CeP}(2.5)$ catalyst. a XRD, b FT-IR 


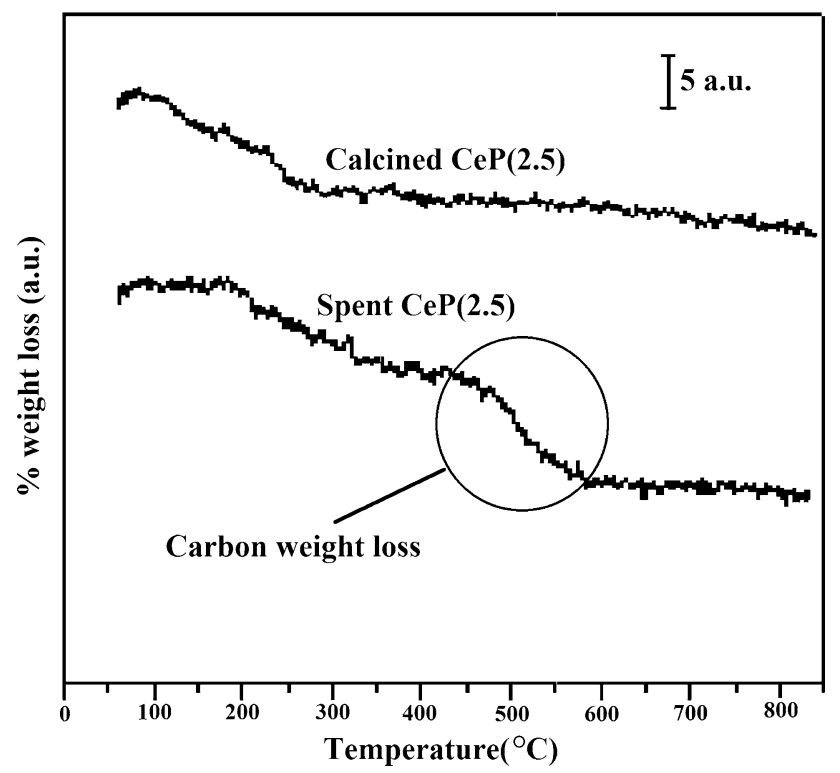

Fig. 11 TGA studies for $\mathrm{CeP}(2.5)$ and spent $\mathrm{CeP}(2.5)$

Table 4 Results for carbon deposits using CHNS analysis

\begin{tabular}{llllll}
\hline Catalyst & $\begin{array}{l}\text { Carbon } \\
(\%)\end{array}$ & $\begin{array}{l}\text { Hydrogen } \\
(\%)\end{array}$ & $\begin{array}{l}\text { Nitrogen } \\
(\%)\end{array}$ & $\begin{array}{l}\text { Sulphur } \\
(\%)\end{array}$ & $\begin{array}{l}\mathrm{H} / \mathrm{C} \\
\text { ratio }\end{array}$ \\
\hline $\begin{array}{c}\text { Calcined } \\
\text { CeP(2.5) }\end{array}$ & 0.11 & 0.569 & 0.00 & 0.00 & 5.17 \\
$\begin{array}{c}\text { Spent } \\
\text { CeP(2.5) }\end{array}$ & 9.14 & 0.685 & 0.00 & 0.00 & 0.075 \\
\hline
\end{tabular}

that the carbonaceous species deposited on the surface of catalyst cause deactivation of the catalyst which further decreases the activity during time on stream of LA acid dehydration.

\section{Conclusion}

Cerium phosphate catalysts are found to be highly active and selective during the vapor-phase dehydration of lactic acid to acrylic acid. Dehydration of lactic acid to acrylic acid was carried out over the cerium phosphate catalysts having different $\mathrm{Ce} / \mathrm{P}$ mole ratios ranging from 0.5 to 3.0. Under the optimized reaction conditions $\left(380^{\circ} \mathrm{C}\right.$, $\mathrm{WHSV}_{\mathrm{LA}}=1.74 \mathrm{~h}^{-1}$ ), the catalyst with $\mathrm{Ce} / \mathrm{P}$ mole ratio 2.5 was identified as the best performing catalyst among the prepared catalysts in terms of LA conversion (99.5\%) and AA selectivity (64.2\%). The catalytic performance depends strongly on the ratio of acidic/basic sites on the catalyst surface. AA selectivity was found to be highest at acid-base balance factor $=0.56$. The deactivation studies further reveal that the decrease in the conversion of LA is due to formation of carbonaceous species on the catalyst surface via the degradation of organic moieties.

Acknowledgments The authors N. Nagaraju, V. Pavan kumar, A. Srikanth and N. Pethan Rajan thank the Indian Institute of Chemical Technology, Hyderabad and CSIR, New Delhi, for the award of Senior Research Fellowships.

Open Access This article is distributed under the terms of the Creative Commons Attribution 4.0 International License (http:// creativecommons.org/licenses/by/4.0/), which permits unrestricted use, distribution, and reproduction in any medium, provided you give appropriate credit to the original author(s) and the source, provide a link to the Creative Commons license, and indicate if changes were made.

\section{References}

1. Gallezot P (2012) Conversion of biomass to selected chemical products. Chem Soc Rev 41:1538-1558

2. Fan Y, Zhou C, Zhu X (2009) Selective catalysis of lactic acid to produce commodity chemicals. Catal Rev 51:293-324

3. Dusselier M, Wouwe PV, Dewaele A, Makshina E, Bert FS (2013) Lactic acid as a platform chemical in the biobased economy: the role of chemocatalysis. Energy Environ Sci 6:1415-1442

4. Jin F, Enomoto H (2011) Rapid and highly selective conversion of biomass into value-added products in hydrothermal conditions: chemistry of acid/base-catalysed and oxidation reaction. Energy Environ Sci 4:382-397

5. Wang HF, Liu CL, Dong WS (2013) Highly efficient production of lactic acid from cellulose using lanthanide triflate catalysts. Green Chem 15:2091-2095

6. Bethesda MD (1993) US Department of Health and Human Services, Hazardous substances Data Bank (HSDB, online database), National Toxicology Information Program, National Library of Medicine

7. Budavari S, Rahway NJ (1989) The Merck Index. An encyclopedia of chemicals, drugs, and biologicals, 11th edn. Merck and Co., Inc., Rahway

8. Lin MM (2001) Selective oxidation of propane to acrylic acid with molecular oxygen. Appl Catal A 207:1-16

9. Weissermel K, Arp HJ (2003) Industrial organic chemistry, propene conversion product, vol 11, 4th edn. Wiley-VCH, Weinheim, pp 291-296

10. Holmen RE (1958) Production of acrylates by catalytic dehydration of lactic acid to alkyl lactates. Assignor to Minnesota Mining and Manufacturing Company, St. Paul, Minn. A corporation of Delaware US patent 2859240, White Bear Township, Ramsey County, Minn

11. Sawicki RA, Stormville NY (1988) Catalyst for dehydration of lactic acid to acrylic acid. US patent 4729978

12. Paparizos WC, Dolhyj PSR (1988) Catalytic conversion of lactic acid and ammonium lactate to acrylic acid. Shaw LWG all of Ohio Us patent 4786756

13. Zhai Z, Li X, Tang C, Peng J, Jiang N, Bai W, Gao H, Liao Y (2014) Decarbonylation of lactic acid to acetaldehyde over aluminium sulfate catalyst. Ind Eng Chem Res 53:10318-10327

14. Katryniok B, Paul S, Dumeignil F (2010) Highly efficient catalyst for the decarbonylation of lactic acid to acetaldehyde. Green Chem 12:1910-1913 
15. Tang C, Zhai Z, Li X, Sun L, Bai W (2016) Sustainable production of acetaldehyde from lactic acid over the magnesium aluminate spinel. J Taiwan Inst Chem Eng 58:97-106

16. Matsuura Y, Onda A, Ogob S, Yanagisawa K (2014) Acrylic acid synthesis from lactic acid over hydroxyapatite catalysts with various cations and anions. Catal Today 226:192-197

17. Ghantani VC, Lomate ST, Dongare MK, Umbarkar SB (2013) Catalytic dehydration of lactic acid to acrylic acid using calcium hydroxyapatite catalysts. Green Chem 15:1211-1217

18. Yan B, Tao LZ, Liang Y, Xu BQ (2014) Sustainable production of acrylic acid: catalytic performance of hydroxyapatites for gasphase dehydration of lactic acid. ACS Catal 4:1931-1943

19. Matsuura Y, Onda A, Yanagisawa K (2014) Selective conversion of lactic acid into acrylic acid over hydroxyapatite catalysts. Catal Commun 48:5-10

20. Sun P, Yu D, Tang Z, Li H, Huang H (2010) NaY zeolites catalyze dehydration of lactic acid to acrylic acid: studies on the effects of anions in potassium salts. Ind Eng Chem Res 49:9082-9087

21. Zhang J, Zhao Y, Pan M, Feng X, Ji W, Au CT (2011) Efficient acrylic acid production through bio lactic acid dehydration over NaY zeolite modified by alkali phosphates. ACS Catal 1:32-41

22. Sun P, Yu D, Fu K, Gu M, Wang Y, Huang H, Ying H (2009) Potassium modified NaY: a selective and durable catalyst for dehydration of lactic acid to acrylic acid. Catal Commun 10:1345-1349

23. Wang H, Yu D, Sun P, Yan J, Wang Y, Huang H (2008) Rare earth metal modified NaY: structure and catalytic performance for lactic acid dehydration to acrylic acid. Catal Commun 9:1799-1803

24. Blanco E, Delichere P, Millet JMM, Loridant S (2014) Gas phase dehydration of lactic acid to acrylic acid over alkaline-earth phosphates catalysts. Catal Today 226:185-191

25. Blanco E, Lorentz C, Delichere P, Burel L, Vrinat M, Millet JMM, Loridant S (2016) Dehydration of ethyl lactate over alkaline earth phosphates: performances, effect of water on reaction pathways and active sites. Appl Catal B Environ 180:596-606

26. Zhang X, Lin L, Zhang T, Liu H, Zhang X (2016) Catalytic dehydration of lactic acid to acrylic acid over modified ZSM-5 catalysts. Chem Eng J 284:934-941

27. Näfe G, López-Martínez MA, Dyballa M, Hunger M, Traa Y, Hirth Th, Klemm E (2015) Deactivation behavior of alkali-metal zeolites in the dehydration of lactic acid to acrylic acid. J Catal 329:413-424
28. Peng J, Li X, Tang C, Bai W (2014) Barium sulphate catalyzed dehydration of lactic acid to acrylic acid. Green Chem 16:108-111

29. Tang C, Peng J, Fan G, Li X, Pu X, Bai W (2014) Catalytic dehydration of lactic acid to acrylic acid over dibarium pyrophosphate. Catal Commun 43:231-234

30. Zhang Z, Qu Y, Wang S, Wang J (2009) Catalytic performance and characterization of silica supported sodium phosphates for the dehydration of methyl lactate to methyl acrylate and acrylic acid. Ind Eng Chem Res 48:9083-9089

31. Rajesh K, Mukundan P, Krishna Pillai P, Nair VR, Warrier KGK (2004) High-surface-area nanocrystalline cerium phosphate through aqueous sol-gel route. Chem Mater 16:2700-2705

32. Takita Y, Sano K, Muraya T, Nishiguchi H, Kawata N, Ito M, Akbay T, Ishihara T (1998) Oxidative dehydrogenation of isobutane to iso-butene II. Rare earth phosphate catalysts. Appl Catal A Gen 170:23

33. Onoda H, Nariai H, Moriwaki A, Maki H, Motooka I (2002) Formation and catalytic characterization of various rare earth phosphates. Mater Chem 12:1754

34. Ho LN, Nishiguchi H, Nagaoka K, Takita Y (2006) Preparation of mesoporous nanocrystalline cerium phosphate with controllable pore size by using chelating agent. Mater Chem Phys 97:494-500

35. Orel ZC, Internet ZJ (1999) Characterization of cerium dioxide dip-coated films by spectroscopic technique. Vib Spectrosc 3:4

36. Girija D, Halehatty S, Naik B, Sudhamani CN, Kumar BV, Cerium oxide nanoparticles-a green, reusable, and highly efficient heterogeneous catalyst for the synthesis of polyhydroquinolines under solvent-free conditions. X-ray Powder Diffraction Standards, ASTM, Philadelphia, PA, Card 34-394 $\left(\mathrm{CeO}_{2}\right)$

37. Ho C, Yu JC, Kwong T, Mak AC, Lai S (2005) Morphologycontrollable synthesis of mesoporous $\mathrm{CeO}_{2}$ nano- and microstructures. Chem Mater 17:4514-4522

38. Patel P, Chudasama U (2010) Thermodynamics and kinetics of ion exchange of a hybrid cation exchanger, zirconium diethylene triamine pentamethylene phosphonate. Indian $\mathrm{J}$ Chem A 49:1318-1324

39. Bhaumik A, Inagaki S (2001) Mesoporous titanium phosphate molecular sieves with ion-exchange capacity. J Am Chem Soc 123:691-696 